\title{
"De veraneo en la playa": pertencimento e o familiar no turismo de massa no Mediterrâneo
}

\author{
"De veraneo en la playa": \\ Belonging and the Familiar in Mediterranean \\ Mass Tourism \\ Javier Caletrío
}

\section{Introdução}

Já faz um tempo que Jacobo está acordado, mas seus olhos continuam fechados. Feixes de luz escorrem pelas venezianas invadindo a calmaria de seu quarto, uma calmaria interrompida apenas pelo movimento ocasional e intuitivo de sua perna buscando a parte fresca da cama. Estes são os prazeres sublimes do verão. Demorando-se

Javier Caletrío é doutor em sociologia pela Universidade de Lancaster, Grã Bretanha, e pesquisador associado no Centre for Mobilities Research, da Universidade de Lancaster (j.caletriogarcera@lancaster.ac.uk). Artigo recebido em 31 de dezembro de 2010 e aprovado para publicação em 29 de março de 2011. 


\section{Javier Caletrío}

na cama, ele vai acordando devagar para o mundo familiar que o cerca: o frescor liso dos cantos intocados da cama enquanto a manhã esquenta, $o$ cheiro aromático da velha mobília de madeira, os pardais no jardim e lá em baixo as vozes de seus avós conversando durante o primeiro café matinal. É o primeiro dia das férias. Ele adia o momento de se juntar aos avós para contemplar a imagem mental do verão que o aguarda, um verão de conversas sem fim na praia, no calçadão, no café, no jardim. Nada de aulas ou horários, nada de relógios ou noites curtas. Um verão para não fazer nada. Memórias de verões passados fazem seus lábios esboçarem um leve sorriso. Finalmente de férias, finalmente em casa.

Jacobo tomará o café da manhã com a família no jardim da villa, ajudará seus pais a fazer as compras no mercado local e irá à praia ao meio-dia. Mas, ao pisar na praia, sua figura não se diluirá na massa impessoal de corpos bronzeados que já se tornou a imagem paradigmática das praias do Mediterrâneo espanhol. Ao contrário, o passeio à beira-mar de Jacobo será um reencontro com amigos de longa data e conhecidos. Sua passagem ao longo da praia sinaliza a existência de itinerários histórico-geográficos alternativos na evolução do turismo de massa que não correspondem perfeitamente às imagens normalmente associadas a conhecidos balneários mediterrâneos, as imagens dos pacotes turísticos de excursões de 15 dias, cuja projeção já vai além do discurso popular e alcança a esfera acadêmica.

Jacobo não é um turista, pelo menos não no sentido acadêmico de uma pessoa que deixa para trás os ambientes conhecidos do dia-a-dia em busca de novidades ou do exótico. Tampouco é um turista "de massa", no sentido mais cotidiano e pejorativo, denotando um membro passivo pertencente a um coletivo dócil, atraído pelo famoso trio sol-praia-mar. Contudo, se pessoas como Jacobo abandonassem as praias da Espanha continental, muitas ficariam desertas e a imagem tradicionalmente associada ao turismo de massa aos poucos se apagaria, pois que estes logradouros não são os espaços por primazia dos pacotes para turistas. Eles pertencem aos veraneantes, uma expressão espanhola usada para designar "todos aqueles que sempre passam o verão em determinado lugar".

$\mathrm{O}$ foco do veraneantes é sempre poder garantir a reprodução de redes sociais, traço que problematiza a associação muitas vezes feita entre o turismo e visitas a pontos turísticos. A origem doméstica e, muitas vezes, local do veraneante, o seu status ambíguo na condição simultânea de anfitrião e hóspede, bem como sua influência na determinação da interação social em vários balneários desestabilizam a visão já bastante arraigada do turismo de massa no Mediterrâneo como uma força que invade e corrompe culturas locais, retratadas como intocadas, homogêneas e indefesas. Observar os veraneantes ajuda a ilustrar a complexidade da 
paisagem de lazer no Mediterrâneo, que surge a partir dos padrões diversos e interrelacionados de atracamento e mobilidade ou formas interdependentes de viajar e morar (dwelling-in-travelling)(Clifford, 1989; Urry, 2000; Obrador, 2003).

Este artigo visa a destacar a importância e os efeitos paradoxais do familiar na criação das paisagens mediterrâneas. Todavia, é importante ressaltar que, ao passo que o veraneo constitui um estilo de férias em que certas formas do familiar se expressam vividamente, não há intenção alguma de caracterizar o veraneo em contraposição a outros estilos de viagem, em que o familiar se faz presente sob uma fachada diferente, menos evidente ou mais sutil. Não há tampouco aqui a intenção de elaborar uma nova tipologia do turista. Com efeito, meu objetivo será destacar uma série de práticas e discursos que produzem lugares, afetos e sentidos de pertencimento particulares, compartilhados por grupos sociais, classes e nacionalidades diversas.

Nesse sentido, este artigo busca mostrar de que forma o veraneo adquire expressão por meio de um conjunto de realidades locais, nacionais e transnacionais, tais como o movimento de êxodo rural, migrações internacionais e legados coloniais. Nesse sentido, o veraneo é um lembrete de que é preciso enxergar o turismo como um fenômeno cultural e socialmente imbricado, cujos contornos indefinidos estão sempre em movimento. $\mathrm{O}$ veraneo remete obrigatoriamente ao argumento de Adler (1989) de que a história do turismo na Europa deve ser interpretada como a história de uma miríade de configurações estilizadas de convenções sociais e culturais, por vezes antigas, por vezes novas, modos de viagem, sonhos coletivos e imaginários, conhecimento médico e científico, hospitalidade e instituições políticas.

Os dados apresentados neste artigo foram colhidos a partir de sete grupos focais, integrados por 41 participantes, e de 30 entrevistas longas feitas com veraneantes em quatro balneários da Costa Blanca espanhola, entre os verões de 2000 e 2001 . Uma nova pesquisa realizada em 2010 serviu para confirmar e elaborar com mais profundidade os resultados aqui apresentados. Foram entrevistados veraneantes de diferentes faixas sociais: da classe A (status: classe média alta; ocupação: cargos administrativos, gerenciais ou profissionais altos) até a classe C2 (status: classe trabalhadora de nível técnico; ocupação: trabalho manual técnico), sendo que a maioria dos entrevistados em Benidorm era oriunda da classe B (status: classe média; ocupação: cargos administrativos, gerenciais ou profissionais intermediários) e $\mathrm{C} 1$ (status: classe média baixa; ocupação: cargos de supervisão ou de escritório, cargo gerencial, administrativo ou profissional júnior) e em Altea, Calpe e Moraira das classes A e B.

Na primeira parte do artigo, destaco a significação quantitativa do fenômeno do veraneo na Espanha. Na segunda, faço uma breve discussão da noção de "familiar", elaborada pelas teorias sociais da viagem e do turismo. Na terceira, 
tomando como base dados qualitativos da Costa Blanca, examino o papel do veraneo no encontro com paisagens de turismo mediterrâneas. Por fim, na conclusão, incluo sugestões para pesquisas futuras.

\section{O significado do veraneo}

Embora informações sobre a importância quantitativa dos veraneantes sejam escassas, dados existentes relativos a residências secundárias podem fornecer uma indicação mais confiável, ainda que indireta, da escala gigantesca desse fenômeno. No final da década de 1990, o índice de domicílios espanhóis que eram residência secundária era de $16,5 \%$ - a porcentagem mais alta na União Européia (conforme tabela abaixo). No entanto, a porcentagem de lares com acesso a uma segunda residência, de propriedade ou alugada por parentes ou amigos, era ainda mais alta: 21\% (IET, 2000). Em 2003, esta cifra subiu para 34,85\%, uma taxa de crescimento de 1,7\% ao longo dos cinco anos anteriores. Em 2003, 2/3 de todas as viagens feitas por espanhóis tinham como destino uma residência secundária.

Tabela 1. Porcentagem de residências secundárias

\begin{tabular}{ccccccc}
\hline Espanha & Grécia & Itália & França & $\begin{array}{c}\text { Reino } \\
\text { Unido }\end{array}$ & Alemanha & $\begin{array}{c}\text { União } \\
\text { Europeia }\end{array}$ \\
\hline $16,5 \%$ & $15,3 \%$ & $11,9 \%$ & $10,2 \%$ & $5 \%$ & $4,7 \%$ & $8,6 \%$ \\
\hline
\end{tabular}

Fonte: EU Household Panel.

A demanda internacional por esse tipo de acomodação também é notável. Em Majorca a porcentagem de visitantes usufruindo de uma residência secundária sobre o total de chegadas na ilha era de $67 \%$ para os alemães, $27 \%$ para os britânicos, $66,5 \%$ para os franceses e $44 \%$ para os espanhóis (CAIB, 1997; Duhamel, 2000). Uma indicação do grau de familiaridade com o local visitado é sugerido pelas taxas de propriedade. Mais de $70 \%$ de visitantes do norte europeu, fazendo uso desse tipo de acomodação na Espanha, usavam uma propriedade própria ou a de um parente ou amigo, enquanto que os 30\% restantes alugavam (IET, 2000). O Instituto de Proprietários Estrangeiros e associações de incorporadoras imobiliárias estimam que em 1998 o total de europeus com uma propriedade na Espanha chegava a 1.100.000. Este número subiu para 1,5 milhões em 2001 e, segundo estimativas, chegaria a 1.750 .00 até 2003 (FIPE, 2002).

O fenômeno da residência secundária é particularmente evidente na região de Valência, onde foi realizada a pesquisa de campo que inspira este artigo. 
A porcentagem de lares na região de Valência com uma segunda residência aumentou de 19,8\% em 1998 para 22,8\% em 2002 - ou seja, praticamente um quarto dos lares na Região Valenciana eram proprietários de um segundo imóvel. Esta é a porcentagem mais alta na Espanha. De acordo com os dados confiáveis para o ano de 1992, fornecidos pela Secretaría General de Turismo, na região de Valência havia 78.210 leitos no setor hoteleiro e 2.219.000 leitos disponíveis fora da rede hoteleira (acomodações de aluguel - self-catering, residências secundárias, inclusive aquelas não registradas) (Monfort e Ivars 2001: 28). Estes números incluem tanto a costa quanto o interior da região.

Outro estudo apresenta o número de 1.493.705 leitos para turistas ao longo dos principais balneários litorâneos, $92 \%$ dos quais correspondem a acomodações não hoteleiras (i.e. villas, apartamentos, casas geminadas) (Fundación Cavanilles, 1994). Em balneários valencianos, a maioria das residências secundárias é constituída por imóveis próprios e não alugados, com a exceção de Benidorm (AVT, 2000b). Faltam dados abrangentes e confiáveis com relação ao índice de proprietários, ainda que pesquisas parciais disponíveis para dois balneários bastante representativos indiquem $75 \%$ e $64,9 \%$ (AVT 1999). ${ }^{1}$

O predomínio de veraneantes em vários balneários continua sendo amplamente ignorado na academia. Apesar de seu capítulo bastante perceptivo acerca das férias de verão e das residências secundárias, o estudo de Löfgren (1999) não chega a reconhecer a popularidade dessa prática no sul europeu e caracteriza o Mediterrâneo contemporâneo como uma região que sobrevive ao ritmo dos pacotes de duas semanas. Contudo, a prática do veraneo confere à paisagem litorânea do Mediterrâneo espanhol um ritmo diferente. Ou, para ser fiel à analogia braudeliana utilizada por Löfgren, a vida no Mediterrâneo palpita ao ritmo de não apenas um, mas de uma miríade de ritmos, alguns dos quais são resultantes, giram em torno ou estão imbricados com a prática do veraneo.

\section{A atração do familiar e os estudos do turismo}

Os ritmos do veraneo adquirem contornos e sentidos de acordo com sua relação com outros lugares e formas de lazer e trabalho. "Altea", segundo relato de uma veraneante, "não é um lugar para fazer turismo ou para ver atrações, trata-se de um lugar para ficar, para descansar, para encontrar as pessoas". A simplicidade desta resposta bastante direta sugere o sentido relacional do lugar e também os três discursos-chave que estruturam o veraneo como um estilo de viagem: relaxamento ("curtir a preguiça"), socialização ("somos uma família"), e uma ligação com o lugar ("aqui é nosso lar"). Um dia típico do veraneante passa pela socialização com parentes e amigos de uma forma descontraída (acerca das "mobi- 


\section{Javier Caletrío}

lidades informais - laid back", ver Haldrup, 2005). Tal estilo de vida envolve um padrão de mobilidade espacial restrito, gravitando em torno da praia e do calçadão, o cenário de uma gama de práticas mundanas como caminhar, comer e beber em bares e lanchonetes, ou tomar sol e banhar no mar, repetidos com precisão cirúrgica dia após dia do começo até o final de suas férias:

De certo modo, para a gente, a casa é um supérfluo. Você vai à praia de manhã, encontra seus amigos, depois talvez você tome uma cerveja e nade por um tempo e depois coma uma salada, e às vezes a conversa está boa e você decide comer umas sardinhas do bar em vez de em casa (a villa). Então você acaba passando o dia todo lá. E daí à noite você pode pedir para o Angel, o dono do bar, cozinhar uma paella para todo mundo e depois dar um mergulho no mar e daí você acaba voltando para casa à uma ou às duas da manhã. $\mathrm{E}$ assim o verão vai passando (Jesús, 45 anos, de Valência, Espanha, gerente bancário, frequentador de Moraira).

Como ilustrado por esta citação, o dia-a-dia é pontuado por rituais cotidianos valorizados, tais como as três refeições principais do dia, a siesta, uma bebida no final da tarde no calçadão da praia e as conversas que varam a noite com os amigos e parentes, os quais conferem um sentido de familiaridade. São justamente esses ritmos, aparentemente banais e altamente previsíveis do cotidiano em companhia dos entes queridos, que conferem um significado especial e valorizam as férias e o local onde elas transcorrem.

Ao tentar decifrar o significado desta previsibilidade e familiaridade por meio de teorias sociais do turismo, somos levados seja a descartar o veraneo como uma forma de turismo, seja a não conseguir compreender seu potencial emancipatório. Ao tomar como pressuposto a dicotomia entre casa e alhures (home and away), na qual a casa é associada ao familiar e o alhures à novidade e ao exótico, o familiar tende a ser compreendido como tudo aquilo que o turista deixa para trás. Em um de seus escritos mais antigos sobre o assunto, Urry (1990: 2-3) argumenta que o turismo envolve o movimento de pessoas a "um novo lugar ou a novos lugares", que logradouros turísticos são locais "fora do comum" e que há uma "clara intenção de voltar para 'casa".

Quando o familiar aparece na experiência de viagem do turista, a literatura acadêmica tende a apreendê-lo como o resultado da crescente padronização do cotidiano. Relatos do turismo como uma busca pelo autêntico associam o familiar à comodificação e à perda da autenticidade (MacCannell, 1973). Essa mesma linha de argumentação é levada adiante por Ritzer, em sua "tese da 
macdonaldização", segundo a qual a crescente comodificação dos destinos turísticos resulta em, ou são expressas pelos, produtos, serviços e experiências altamente padronizados (Ritzer, 1996). Voltando o foco para o turista, autores como Brunner (1991) ou Rojek (1994) levantam dúvidas quanto ao potencial do turismo como instância de auto-desenvolvimento ou como "válvula de escape", pois turistas inevitavelmente carregam uma "bagagem" cultural enquanto membros de uma classe, gênero, raça ou nação específica.

Uma leitura cuidadosa das historiografias da viagem ou do turismo sugere, no entanto, múltiplos e complexos entrelaçamentos entre casa e alhures (ver Pemble, 1987). Estes entrelaçamentos e o efeito ontológico da "bagagem cultural" nos logradouros têm sido cada vez mais reconhecidos dentro do performative turn em curso nos estudos do turismo (cf. Edensor, 1997; Crang \& Coleman, 2002; Bærenholt, Haldrup, Larsen \& Urry, 2005). Numa tentativa de repensar o lugar do turismo na modernidade, Minca e Oakes argumentam que "o estudo da viagem também deve levantar questões sobre o significado de casa, do pertencimento, acerca de como lugares são criados e recriados" (2006: 1). Eles percebem o espaço como parte intrínseca da prática da viagem e a viagem como parte intrínseca do espaço e das práticas de criação do lar: "criação do espaço está permeada com a viagem e toda a bagagem que é transportada ao mesmo tempo: a diferença, o estranhamento, a alienação, a nostalgia, a saudade de casa, a inspiração, o medo, a frustração, expectativas correspondidas e desapontadas" (2006:1).

Num veio similar, críticos feministas e pós-colonialistas clamam por um "enquadramento alternativo para repensar o lar e a imigração de modo que a discussão se abra para além de oposições como stasis vs. transformação, ou presença vs. ausência" (Ahmed, Castañeda Fortier \& Sheller, 2003: 1). Crang aponta que

o turista busca a viagem para se fazer presente em um lugar, mas à medida que examinamos estes lugares nos damos conta que estes encontram-se perfurados por ausências em que terceiros distantes, removidos espacial e temporalmente, assombram os logradouros (2006: 49).

Tal atenção minuciosa à complexidade e à contingência entre o lar e o longe sempre mostra como, para muitos, a viagem também é uma forma de chegar em casa, quando o objetivo da viagem é visitar famílias e parentes espalhados em diferentes lugares (Larsen, Urry, e Axhausen, 2007; Urry, 2000). É justamente esse caminho de categorias interrompidas e dualismos que eu seguirei para examinar o familiar no contexto do veraneo. 


\section{Javier Caletrío}

\section{A performance do familiar: habitus e a praia}

A prática do veraneo é paradigmática das formas de estilos de viagem em que o destino é a casa e encontrar entes queridos é crucial.

As pessoas e os lugares aparecem de forma tão entrelaçadas e imbricadas nos relatos dos veraneantes na Costa Blanca que um termo frequentemente substitui o outro:

Bea. Aqui a praia é muito boa, calma e tranquila, e a vida noturna do outro lado da praia é nada mal. Gostamos muito de Benidorm. (...)

Andrea. Você sabe o que acontece? O que acontece é que também temos um forte laço afetivo com Benidorm.

Pierre. Não, também não é a palavra certa. A palavra certa é "sobretudo".

Bea. Sim, você tem razão.

Alfredo. É todo um conjunto de coisas. Tem as pessoas que você realmente aprecia e aquelas que você conhece há muito tempo. São as pessoas que você só vê uma vez por ano, e é só aqui que nos vemos. Além disso, tem toda a tranquilidade... Mas sim, nossos sentimentos por esse lugar são muito importantes. Você tem que levar em conta que estamos vindo aqui há muitos anos. (...) É claro, gostamos da praia, mas quando você pergunta por que nós viemos vamos dizer que gostamos do sol, da praia e tudo, mas, mas para nós, para mim pelo menos, é por causa das minhas pessoas.

essas pessoas.

Bea. A gente vem pela praia, pelo sol, pela brisa ...com

Pierre. Não tem como conceber essas coisas separadamente.

Alfredo. Quando a Andrea diz "Eu preciso de Benidorm", ela não está se referindo a Benidorm em si ou a esta praia em particular. Ela quer dizer que ela precisa vir a Benidorm, a este lugar, esta praia e ver esta ou aquela pessoa.

(Jovens profissionais de Madri e Navarra, na Espanha, e em Paris, França, frequentadores de Playa de Poniente, em Benidorm). 
Estes jovens profissionais demonstram uma relutância em dar maior prioridade ao lugar do que às pessoas e apresentam ambos como entrelaçados. A comunhão entre o lugar e as pessoas sublinha as práticas de home-making, isto é aquelas que conferem um sentido de lar e pertencimento, assim como a noção de lugar dos veraneantes na Costa Blanca. Mas tais relacionamentos são contingentes. O ponto óbvio, porém, que importa ressaltar, é que as pessoas mudam e os lugares também. Isto é algo que Löfgren (1999) não reconhece suficientemente em sua descrição, de resto excelente, das "cottage cultures" (culturas de chalé) na Escandinávia e nos Estados Unidos. Uma vez que o engajamento de um veraneante com um balneário configura-se como de longo prazo, a negociação dessa relação através de sua biografia e através de gerações dentro da mesma família é um componente essencial da experiência do veraneo. A parte restante do artigo oferece uma introdução necessariamente sucinta à dinâmica dessa relação na Costa Blanca. Um ponto de entrada para examinar esta questão é a vivência da praia como um lugar familiar. A praia é o espaço público par excellence em cidades-balneário e o lugar onde a "ligação afetiva" à qual Andrea se refere se exprime de forma mais viva. ${ }^{2} \mathrm{Na}$ minha pesquisa, a praia também é o lugar onde foi realizada a maioria das entrevistas com veraneantes.

A praia é um lugar familiar no sentido duplo de um lugar conhecido e um lugar de família, um lugar onde veraneantes socializam com suas famílias e onde famílias interagem com outras famílias - a praia constitui uma experiência de rotina. Contudo, tal forma específica de viver a praia precisa ser aprendida (Lencek \& Bosker, 1998; Löfgren, 2001). Ela implica a aquisição de habilidades em uma série de atividades e modos de ver, sentir cheiros, tocar, ouvir e se mexer considerados apropriados, naturais, naquela praia: visitar a praia toda manhã mais ou menos no mesmo horário, passear no calçadão de uma certa maneira, posicionando a toalha de praia e o guarda-sol no mesmo local todo dia, olhar para as pessoas e o mar de uma forma específica, conversar com amigos e parentes, reencontrá-los todo ano ou de vez em quando, no intervalo de algumas semanas, compartilhar memórias - a festa da noite anterior ou anedotas de infância -, fazer as crianças e os jovens participarem da lembrança dessas histórias, nadar até lugares determinados, coletar certas plantas ou animais etc. Pelo engajamento contínuo com este conjunto de práticas, os veraneantes adquirem uma disposição de agir, sentir e viver a praia de um modo determinado. Tal disposição de viver a praia como familiar é algo que os veraneantes adquirem como um habitus.

Acadêmicos que utilizam a teoria do juízo do gosto de Bourdieu retratam os balneários como lugares em que identidades são performadas e pressupõem uma intensa competição entre lugares para atrair turistas cada vez mais dotados de mobilidade e discernimento (Urry, 1990; Munt, 1994; Shaw \& Wil- 


\section{Javier Caletrío}

liams, 1997). Contudo, os veraneantes exibem uma incrível fidelidade ao lugar, mesmo após perdas de status decorrente da expansão de construções. Isso sugere que uma dinâmica mais complexa está por trás da vivência do lugar. Quando Eva descreve Altea como um lugar que "não é como Benidrom" e acrescenta que "se trata de um vilarejozinho simpático e, além disso, lá você se sente em casa", ela está participando de uma batalha classificatória em que busca distinguir-se dos "turistas de Benidorm", "turistas vulgares" ou apenas "turistas menos distintos". Mas ela também está exprimindo algo mais complexo, pessoal e específico, que antecede as convenções de classes e a política entre elas, que vai além delas ou que está em paralelo a elas. $\mathrm{O}$ fato de Eva sentir-se à vontade ou confortável é decorrente, em parte, do engajamento contínuo com a materialidade do lugar e das atividades que este possibilita. Essa disposição afetiva possui uma afinidade maior com o habitus de Mauss (1979) do que com o de Bourdieu. Claramente, o habitus de Mauss - as técnicas do corpo-é intrinsecamente social, porém menos determinado por classe social e logo deixa mais espaço para a inovação e a transformação e uma gama mais abrangente de contextos e experiências capazes de moldar as disposições corporais e afetivas. Como resultado, o senso de distinção derivado da competência de um veraneante no uso da praia não implica necessariamente em elitismo ou esnobismo, pelo menos nem sempre nem em todo contexto e situação.

\section{Pertencimento e nostalgia}

A analogia feita por Ana entre a praia e sua casa exprime um sentido de familiaridade e intimidade. Trata-se de um sentido de familiaridade que brota do engajamento prático com a materialidade da praia na companhia de outros. Ela se refere a um tipo de experiência em que a "paisagem está conosco, não contra a gente, assim como nós fazemos parte dela" (Ingold, 1993: 154). Esta familiaridade com a paisagem envolve uma ligação ao lugar que a expressão mi pueblo consegue captar. O termo pueblo significa literalmente vilarejo. Mi pueblo poderia ser traduzido como "minha cidade natal" ou "a cidade da minha família" e evoca um sentido de pertencimento e um lugar onde é possível se sentir bem-vindo ao ver os rostos familiares:

Depois de passar tanto tempo vindo a Benidorm, você acaba vendo-a como outras pessoas urbanas enxergam ou vivenciam o pueblo de onde seus pais vieram, um lugar que você aprecia. Meus pais 
não têm um pueblo já que eles nasceram em Lleida, portanto Benidorm é o meu pueblo.

(Sonsoles, 24 anos, de Lleida, na Espanha, frequentador de verão da Playa de Poniente desde seu nascimento)

Me sinto muito ligada a esse lugar. É esse o lugar que vem a minha mente quando me pergunto: "para onde vou quando me aposentar?" Respondo: "Eu virei para Moraira". (...) Eu vejo Moraira como se fosse o meu pueblo. Toda vez que venho a Moraira sinto-me como se estivesse voltando para meu pueblo. Você entende? Sabe as pessoas que tiveram que migrar de seus pueblos quando eram jovens e depois passaram a voltar todo ano durante as férias para visitas a família, para rever seu lugar? (...) Toda vez que venho aqui é como se estivesse voltando ao meu pueblo. Eu tenho que trabalhar em Valência, mas todo final de semana vou ao meu pueblo, para o lugar onde... para minhas raízes.

(Ana, 51 anos, moradora de Valência, na Espanha, frequentadora de Moraira).

O conteúdo afetivo das palavras mi pueblo está relacionado, como Cristina indica, ao êxodo rural que esvaziou uma porção enorme do interior da Espanha e de sua população, um processo que atingiu proporções gigantescas durante as décadas de 1960 e 1970 e que ainda é fonte de preocupação em várias regiões. Este declínio demográfico tem ocorrido por todo o interior rural da Europa, sendo que os países mais agrícolas do Sul estão entre os mais afetados. Consequentemente, uma considerável fração da população urbana na Espanha, Itália e Grécia possui hoje acesso a uma segunda residência no interior, seja esta um imóvel próprio ou de parentes. A cidade natal e as áreas rurais são uma presença persistente na vida de várias famílias urbanas, não apenas por causa das visitas frequentes feitas a parentes e pelas viagens a descanso, mas também no cotidiano, por intermédio, por exemplo, do consumo de comidas e bebidas locais e muitas vezes artesanais. Alusões no dia-a-dia à cidade natal são comumente acompanhadas por altas doses de nostalgia e fazer uma visita pelo menos uma vez por ano, principalmente na época do festival de verão local, é considerada uma obrigação e como uma maneira de "não perder o contato com as raízes".

Para aqueles nascidos num vilarejo, a expressão mi pueblo é ao mesmo tempo fatual - uma identidade adquirida pelo acaso - e uma ligação afetiva, isto é, uma escolha deliberada. Em balneários, a maioria dos veraneantes está afirmando apenas uma ligação afetiva e uma vontade de pertencer a um lugar, mas 


\section{Javier Caletrío}

frequentemente se trata de uma pré-disposição a pertencer, determinada por escolhas familiares anteriores. Para entender o investimento feito por Ana no sentido de atribuir um sentido de casa a Moraira, o foco deve se voltar menos para ela individualmente e sim para a dinâmica geracional de sua família. A prática do veraneo é um afazer familiar cuja coreografia inclui diferenças em ritmos de vivência de acordo com a idade, o gênero e padrões particulares de atividades e ligação (ou desprendimento) com a vida e o lugar familiar. Esta conexão com a vida familiar é crucial para compreender a lógica temporal do veraneo e das paisagens de lazer no Mediterrâneo espanhol.

Para ilustrar este ponto volto minha atenção para Beatrice, uma cidadã francesa que visita Moraira há mais de trinta anos. Desde que Beatrice e seu marido se aposentaram, no final dos anos 1990, eles passam a primavera e o verão em Moraira e o outono e o inverno em Pau, na região dos Pirineus, esquiando e fazendo caminhadas, coisas que ela considera cruciais na sua vida durante o inverno. Atualmente, ela se descreve como uma pessoa que vive uma vida dupla, uma na França e outra em Moraira. No trecho transcrito abaixo, ela descreve esse sentido de pertencimento como algo que envolve a criação de vínculos rizomáticos em diferentes lugares:

Beatrice: Eu sabia que quando as crianças crescem o que elas não gostam é de estar sempre viajando, mas de estar sempre vendo os mesmo amigos, praticar esportes, sabe, ter raízes, raízes próprias. Elas gostam é de mudar para um lugar diferente, mas mantendo as raízes. Por exemplo, eu não gosto do costume de vários franceses de cada ano visitar um lugar diferente. E nós ainda viajamos para outros lugares, mas em outra época do ano, não durante o verão.

\section{FC. Mudar sem mudar?}

Beatrice: Sim, mudamos de lugar, mudamos tudo, mudamos de língua, comida. Também mudo minhas leituras porque leio muito em espanhol, e mudamos de amigos. E ainda assim viemos a nossa casa, um lugar onde temos raízes.

(Beatrice, 60 anos, aposentada, moradora de Pau, França, frequentadora de Moraira)

Na medida em que as qualidades estéticas e a matiz social do lugar influenciaram a decisão de Beatrice de adquirir propriedade e "criar raízes" em Moraira, a história dela pode ser vista com uma forma de "pertencimento eleti- 
vo", tal como conceituado por Savage, Bagnall e Longhurst (2004). Segundo esses autores, a ligação com o lugar não é decorrente da familiaridade com uma comunidade caracterizada por uma sociabilidade do tipo face-a-face, mas de um sentido relacional de localidade, uma capacidade de avaliar o lugar em relação a outros e de encaixar a sua biografia particular em sua dinâmica social, cultural e econômica.

Para Beatrice, as vantagens proporcionadas pelo lugar são aspectos-chave dentro de estrutura de consciência relacional, principalmente as vantagens proporcionadas pela praia: "Naquele momento, eu tinha dois meninos aventureiros e pensava que Las Landas [um balneário francês onde ela tinha uma segunda residência] não era um lugar seguro para passar as férias". À medida que seus filhos foram crescendo, ela começou a passar mais tempo em Moraira, onde a ausência de correntes marítimas torna o banho de mar mais seguro. Seus filhos preferiam Moraria como o lugar das férias, pois lá tinham mais liberdade e ela acabou vendendo a casa em Las Landas.

A criação de filhos é um elemento central nas performances de veraneo e, neste caso, as vantagens proporcionadas pelo lugar são importantes no desenvolvimento de um sentido de ligação (ver Savage et al., 2004: 62, acerca do pertencimento, criação familiar e o campo educacional). Entrevistados em outros balneários muitas vezes destacaram de que modo o caráter "familiar" da praia e seus atributos físicos "calmos" forneciam a tranquilidade e o relaxamento para pais que não precisariam ficar tão preocupados com os filhos.

Sua sensibilidade aos modos de dar sentido ao lugar em relação a biografias individuais confere ao conceito de pertencimento eletivo um elemento de dinamismo temporal. No entanto, as experiências de veraneo demandam maior atenção a mudanças geracionais e redes sociais emergentes na geração do sentimento de pertencimento. As redes sociais de Beatrice, depois de trinta anos frequentando Moraira e graças à sua habilidade de falar espanhol, idioma também dominado pelos seus filhos, incluem também "nativos" - aqueles nascidos em criados em Moraira -, vários veraneantes espanhóis e não espanhóis e migrantes aposentados.

Um de seus filhos casou-se com uma veraneante espanhola e eles também frequentam a cidade e mantêm uma rede social. As redes sociais estabelecidas em Moraira são mais extensas e duradouras que aquelas deixadas em Las Landas. Moraira torna-se frequentemente ponto de encontro da família, já que agora seus filhos vivem em diferentes lugares na França. Ela também aprendeu a aceitar mudanças nas qualidades estéticas e na interação social do lugar - a fidelidade a uma comunidade face-a-face complementa e, por vezes, compensa a perda dessas qualidades.

Há ainda outro aspecto contido na decisão de Beatrice de "criar raízes" em Moraira que não pode passar despercebido. Ela viveu na Argélia por quatro 


\section{Javier Caletrío}

anos e guarda um afeto por sua paisagem que compartilha afinidades climáticas, botânicas, geológicas e culturais com a Costa Blanca. As vantagens proporcionadas pelo lugar são significantes, na medida em que reativa as memórias do norte da África.

O potencial mimético da paisagem mediterrânea é explicitamente evocado no trecho transcrito abaixo do relato de Marie e Alice, ambas pieds noirs francesas nascidas no norte da África que migraram de volta para França após a independência destas ex-colônias - Argélia, Tunísia) -, explicam o que as levaram a optar por "criar raízes" em Altea: "Compramos o apartamento aqui para criar raízes. Estamos vindo aqui há trinta anos e nossa alegria e prazer são inesgotáveis (...) Sentimos que esse vilarejo nos pertence".

Em momento posterior na entrevista, ao falar de seus sentimentos em relação ao mar, elas desenvolvem o significado que passar as férias na costa do mar Mediterrâneo tem para elas:

Alice. Nós nascemos na beira do mar e agora vivemos em Paris (...) moramos perto do mar no Magreb, Casablanca, Tânger e depois Marselha e depois Paris, que é outro mar povoado por pessoas. Mas eu não posso viver sem Paris. (...) para mim o mar significa a liberdade, a cor.

Marie. E a qualidade de vida, o estilo de vida diferenciado do Mediterrâneo. Quero dizer que ele nos faz lembrar nossas raízes. Você sabia que havia muitos espanhóis e outros de lugares diferentes na Argélia e no Marrocos e nós carregamos esta mistura conosco, somos uma espécie de síntese daquela mistura.

Alice. O mar nutriu nossa juventude, nossa adolescência, nossa infância. Quando olhamos para esse mar nos sentimos bem, reavivamos algo da nossa adolescência, inconscientemente talvez.

FC. Quer dizer que vocês sentem isso quando olham para esse mar ou o mar de forma geral?

Marie. Olha, o Atlântico é muito bonito, mas chove e a água é fria e é muito diferente. Estou falando das cores deste mar, sua luz, os perfumes do campo, a flor de laranjeira, o jasmim. Quando você anda pela praia de La Olla, você passa por um laranjal e um perfume intenso chega até você. Não tem esse cheiro no Atlântico (Marie e Alice, na casa dos 40 anos, parisienses, frequentadoras de verão de Altea há mais de 35 anos). 
O significado do mar Mediterrâneo e da paisagem para Marie e Alice em parte reside na sua capacidade de evocar lembranças de sua infância, no norte da África. Isso é propiciado pelo encontro sensorial com a paisagem. $\mathrm{O}$ aroma do laranjal traz a Marie memórias de infância e um sentido de lugar. Podemos compreender este fenômeno como um exemplo do que Hetherington chama de a praesentia do lugar (Hetherington, 2003; Obrador, 2007). O conceito de praesentia lida com a presença e a confirmação. Nesse caso, o aroma da flor de laranjeira não figura como um metáfora de sua infância, mas como algo que torna presente o ausente - suas memórias de infância. Pela alteridade da materialidade do laranjal e seu aroma, uma memória faz-se presente. A praesentia é revelada pela sensação do aroma. O que é revelado é a memória, mas também o sentido de familiaridade, o sentimento de alguma coisa ou algum lugar conhecido. Marie nota o aroma do laranjal, mas também fala de outras sensações: sentir a mornidão do mar, apreciar a textura de cores e luzes.

Em sua etnografia dos pieds noirs que viajam a Malta, Andrea Smith (2006) descreve reações similares à paisagem, também parecida com a do norte africano. A opuntia é a planta que particularmente provoca as reações mais animadas:

Deleitar-se nessa nostalgia pela paisagem do norte da África culminou no último dia da viagem. Enquanto esperávamos a balsa que nos levaria de Gozo até Malta, estacionamos num morro que dava para a baía. O tempo estava frio e úmido e o sol se punha. Mas bem ao lado das vans estacionadas, ao longo de toda estrada estavam os mais carregados pés de figos de opuntia que já havíamos visto. Aquilo foi demais para eles. Rindo como crianças, os retirantes na van da frente começaram a criar uma comoção, tirando fotos um do outro e vasculhando suas sacolas. Era hora de um banquete de figos deopuntia! (...) Todos começaram a se refestelar naquelas deliciosas frutas maduras (...). Uma senhora, mais tensa e durona, começou a falar entusiasmadamente pela primeira vez durante a viagem. "Ah, isso é exatamente como minha juventude!", ela não parava de exclamar. "Você sabia que faz mais de 33 anos que não como uma dessas?", ela me disse. "33 anos. Como elas me lembram os bons velhos tempos!” (Smith, 2006: 218-219)

Tal momento proustiano é explicado com mais profundidade por Giuseppe, um migrante da Itália que se radicou em Altea depois de vir como turista e que hoje passa o período de férias numa segunda residência, em sua cidade natal na Calábria. No trecho transcrito abaixo, ele fala efusivamente sobre ex- 


\section{Javier Caletrío}

periências sensoriais: o gosto de determinados vegetais que colhe na praia ou os mexilhões crus que come com gotas de azeite e limão, o toque dos seixos ou a gosma dos polvos. Por meio desse repertório performativo, Giuseppe não está "buscando o sentido" daquela paisagem. Em vez disso, ao deparar-se com sua materialidade, ele está adquirindo o sentido de quem ele é e está se reconhecendo como um sujeito particular. Através desse repertório sensorial, Giuseppe está adquirindo um sentido de lugar. Ele desenvolve esse ponto quando incitado a falar sobre o mar:

O que o mar me traz ... esta pergunta está relacionada àquilo que estava falando antes sobre o fato de me identificar com o Mediterrâneo. (...) o que ele me traz são tantas coisas, tantas coisas que eu assimilei desde o começo da infância. Minha primeira memória do mar é uma coisa que nunca vou esquecer. O cheiro do mar... Há tantas coisas... por exemplo, coisas relacionadas à comida. Passei tantas noites perto do mar comendo certas comidas: tomates, melancias, azeitonas, uvas. Todas estas coisas estão muito relacionadas, não estão? Os cheiros, as flores silvestres, os vegetais selvagens que você colhe nas rochas, na beira do mar. Onde nasci, no sul da Itália, esse vegetal é colhido durante o verão e conservado no vinagre. É um tipo de algo que cresce perto da água... esse tipo de vegetal eu costumava comer com um certo tipo de comida em determinados momentos, então não tem como não sentir uma forte identificação. $\mathrm{O}$ mesmo acontece com peixinhos fritos, com os polvos. Por exemplo, estou me referindo à sensação de capturar um polvo e o bater contra as rochas trinta, quarenta vezes para amaciar a carne. $\mathrm{E}$ ao fazer isso ele produz uma gosma, uma secreção pegajosa que aparece quando você limpa o polvo. O que estou tentando lhe dizer é que todas essas coisas são sensações que por estar e crescer perto do mar você pode viver, sensações que aos poucos se tornam parte de você e que você desfruta inteiramente, até o caroço.

O sabor dos mexilhões, o melão, o azeite, o cheiro das flores, do mar, o toque do polvo, todas estas experiências sensoriais criam uma experiência da praia como um lugar onde a paisagem e o corpo se encontram. Esta experiência da paisagem é específica, local e parcial e está preocupada com a confirmação muito mais do que com a representação. Esta forma aproximativa de conhecer, argumenta Hetherington, "ajuda a performar uma subjetividade localizada constituída como um contato parcial e como envolvimento na materialidade desse $\mathrm{Ou}$ tro" (Hetherington, 2003). Tais experiências corporificadas da praia como um 
lugar familiar não estão disponíveis a qualquer um. Ela requer certa habilidade na utilização de formas de conhecimento proximais e performativas. Essa habilidade é adquirida ao longo de uma rotina e é incorporada como um habitus.

\section{Conclusão}

Além das paisagens liminares do Mediterrâneo, ludicamente abordadas por muitos turistas (Inglis, 2000), há outras paisagens a se sobrepor e a intersectar, girando em torno de um reencontro com lugar e pessoas, paisagens e memórias, carregadas de tempo, que testemunham o esforço de veranistas e migrantes no sentido de criar um sentido de casa. A casa é uma parte essencial da viagem e isso se aplica não apenas a práticas do veraneo, mas a outras mobilidades que perpassam e compõem a Costa Blanca: o migrante marroquino ou senegalês em Benitaxtell, na esperança de conseguir os "papéis" para que possa começar a vida na Europa e na saudade dos parentes que deixaram para trás, uma família argelina descansando num posto de gasolina em Moraira, em sua viagem anual a Kabila para reencontrar amigos e parentes, uma família parisiense tentando aproveitar uma semana em Altea para cuidar de feridas familiares, aposentados britânicos migrando e recriando uma little England ou um Mediterrâneo cosmopolita. Ao trazer consigo formas estilizadas de sentir e lembrar, cultivadas em outras geografias e tempos, turistas e migrantes tornam a paisagem espanhola uma realidade multifacetada.

Os relatos apresentados neste artigo sugerem que o encontro dos veraneantes com o lugar não é um processo simples, linear, em parte porque localidades de veraneio são vividas como locais complexos e paradoxais. Em vez de serem vividos como recipientes espaciais fixos de processos socais, os balneários estão sendo vividos como um emaranhado de relacionalidades de outros lugares e paisagens. Poderíamos dizer que os balneários não são logradouros fixos, mas entidades topograficamente complexas que nós colocamos em movimento de diversos modos. Parte desse artigo destacou formas corporais e materiais segundos as quais geografias e paisagens são mobilizadas.

O artigo também descreveu como, por meio de disposições sensoriais e atos de lembrança, geografias e/ou tempos remotos são performados com presenças ausentes que se tornam imbricadas na realidade de resorts turísticos. A heterogeneidade destes planos retorcidos de tempo-espaços, a natureza cada vez mais distorcida destas topografias, associadas a esses padrões de moradia nômade (dwelling-in-travelling) e possibilitadas por eles tornam as experiências de paisagem em balneários um processo complexo e multidirecional. 
O papel da memória e das redes sociais ajuda a explicar porque, com o suposto deslocamento das sensibilidades modernas para um patamar pós-moderno, os resorts mediterrâneos à beira-mar continuam a exercer um apelo inesgotável. Afinal, após tanta destruição ambiental aparente e perda dos status dos balneários, vítimas do excesso de construções, a paixão mediterrânea, para tomar emprestadas as palavras de Pemble, continua viva para as classes trabalhadora, média e alta. Obviamente esta não é única razão capaz de explicar o apelo desses balneários e o poder das distinções de gosto, assim como processos políticos e econômicos não podem ser subestimados. É preciso que haja mais pesquisa empírica, tendo como objeto a relação entre juízos de gosto relacionados à classe social, as vantagens propiciadas pelo lugar, memória, redes sociais e mudanças familiares em nível individual e social. Disso resultaria uma articulação de noções mais dinâmicas de pertencimento eletivo.

Com o boom imobiliário do final da década de 1990, os balneários tornaram-se mais internacionalizados, a ponto de cerca de $50 \%$ dos novos imóveis terem sido adquiridos por cidadãos não espanhóis da União Européia, um crescimento sustentado pela mão de obra fornecida por países do norte da África, do Leste europeu e da América do Sul. Ainda não está claro até que ponto essas circunstâncias estão levando a uma internacionalização das redes sociais tão centrais à prática do veraneo, apesar da existência de evidências sugerindo que essas redes se sobrepassam, ao invés de se cruzarem ou de co-amplificarem seu potencial emancipatório. Com sua recente irrupção nas ciências sociais, o conceito de cosmopolitanismo vai abrindo linhas de pesquisa produtivas (ver Beck \& Sznaider, 2006). Todavia, se a intensificação dos padrões de mobilidade na Costa Blanca está criando o potencial de realização de uma sociedade mais progressista ou de geração de maior conscientização no que diz respeito às interdependências transnacionais, isso é algo a ser conferido.

A maior dificuldade encontrada na tentativa de responder essa pergunta é a falta de evidência histórica sobre a intensidade e as características de disposições cosmopolitas ao longo do tempo e como estas foram possibilitadas por redes sociais e encontros de lugar. Apesar de toda ênfase recente no lema "a história importa" e a despeito da "virada cultural" nos estudos do turismo e sua ênfase na natureza histórica dos estilos de viagem (Adler, 1989), a pesquisa no campo do turismo continua surpreendentemente ahistórica. Nesse sentido, serão necessárias não apenas histórias do turismo, mas também um campo histórico dos estudos do turismo que seja sensível à longue durée dos processos demográficos, sócio-ambientais, tecnológicos, culturais, econômicos e políticos subjacentes à viagem e ao turismo (ver Wallerstein, 2000, para sua defesa de uma ciência social histórica). 
1.Taxa de propriedade de uma segunda residência e número de leitos comparados com leitos hoteleiros.

\begin{tabular}{lcccc}
\hline Cidade & $\begin{array}{l}\text { Número de } \\
\text { residências } \\
\text { secundárias }\end{array}$ & $\begin{array}{l}\text { Leitos em } \\
\text { residências } \\
\text { secundárias }\end{array}$ & Leitos hoteleiros & $\begin{array}{l}\text { Porcentagem de } \\
\text { propriedade de } \\
\text { residências } \\
\text { secundárias }\end{array}$ \\
\hline Oropesa & 7.600 & 30.360 & 1.849 & $75 \%$ \\
\hline Cullera & 14.264 & 57.058 & 1.026 & $64,9 \%$ \\
\hline Benidorm & 38.333 & 153.332 & 33.652 & $27 \%$ \\
\hline
\end{tabular}

Fonte: Agència Valenciana del Turisme, 1999.

Ao exibir uma taxa relativamente alta de propriedade e um predomínio de acomodações em residências secundárias, os balneários de Cullera e Oropesa são os que mais bem representam os balneários na região de Valência. Quando tomamos a taxa de propriedade como uma indicação do grau de familiaridade com o balneário, é importante ressaltar que aqueles que alugam um apartamento ou uma villa são, muitas vezes, frequentadores regulares, embora geralmente com menos poder aquisitivo para adquirir uma segunda residência. Benidorm é a exceção ao modelo predominantemente residencial de turismo na região valenciana. Seus 33.652 leitos em hotéis representam $40,1 \%$ do total da capacidade hoteleira. Apesar de menos do que os outros dois resorts presentes nessa amostra, a taxa de propriedade de re-

\section{Referências bibliográficas}

ADLER, Judith. Travel as a Performed Art. American Fournal of Sociology, 94: 1.3661.391, 1989. sidências secundárias permanece significativa. Aqueles que recorrem a apartamentos alugados incluem frequentadores habituais (algumas famílias alugam repetidamente o mesmo apartamento todo ano) e veranistas de pacote (sobretudo britânicos), que fazem uso de acomodações sem serviços hoteleiros.

2. Embora espaços de acesso restrito, como clubes de tênis e de golfe de elite e marinas, estejam se tornando tendências, a praia e o calçadão continuam sendo o lugar prioritário de socialização para a maioria dos veraneantes, especialmente nos balneários em que os apartamentos são as principais modalidades de acomodação, como em Benidorm, Cullera, Gandia e Oropesa. A praia é o lugar público onde eles passam a maior parte do tempo e muitas vezes um dos únicos lugares públicos ao ar livre.

AGÈNCIA VALENCIANA DE TURISME. Aproximación a la Oferta y Demanda de Viviendas de Uso Turístico en los Municipios de 
Benidorm, Cullera y Oropesa. Valencia: AVT, 1999.

. El Turismo en la Comunidad Valenciana 2000. Valência: AVT, 2001.

El Turismo en la Comunidad Valenciana 2001. Valência: AVT, 2002.

AHMED, Sarah ; CASTAÑEDA, Claudia; FORTIER, Anne Marie \& SHELLER, Mimi. Uprootings/Regroundings. Oxford: Berg, 2003.

BECK, Ulrich \& SZNAIER, Nathan. Unpacking cosmopolitanism for the social sciences: a research agenda. The British Fournal of Sociology, 57, 1:1-23, 2006.

BOURDIEU, Pierre. Distinction. Londres: Routledge, 1979.

BRUNER, Ed. Transformation of Self in Tourism. Annals of Tourism Research, vol. 18, n. 2: 238-250, 1991.

CAIB. Despesa Turística, Mallorca: CAIB, 1997.

CRANG, Mike. Circulation and Emplacement: The Hollowed-out Performance of Tourism. In: MINCA, Claudio \& OAKES, T. Travels in Paradox (ed.). Oxford: Rowman and Littlefield, 2006.

FIPE. Turismo Residencial en España, Boletín FIPE, vol. 5-6, 2000.

HETHERINGTON, Kevin. Spatial textures: place, touch, and praesentia. Environment and Planning $A$, vol. $35, \mathrm{n} .11$, p. 1.933-1.944, 2003.

INGLIS, Fred. The Delicious History of the Holiday. Londres: Routledge, 2000.

INGOLD, Tim. The temporality of landscape. World Archaeology, vol. 25, p. 152-174, 1993.

INSTITUTO ESTUDIOS TURÍSTICOS. Encuesta Turística. Madrid: IET, 2000.
KAPLAN, Caren. Questions of Travel. Postmodern Discourses of Displacement. Durham: Duke University Press Books, 1997.

LENCEK, Lena \&BOSKER, Gideon. The Beach. Londres: Pimlico, 1998.

LÖFGREN, Orvar. On Holiday: A History of Vacationing. Berkeley: University of California Press, 1999.

Learning to be a tourist. Ethnologia Scandinavica, vol. 24, p. 102-105, 2001.

MACCANNELL, Dean. The Tourist. Nova York: Schocken. 1999.

MAUSS, Marcel. Techniques of the body. In: Sociology and Psychology, Londres: Routledge, 1979.

MONFORT, Manuel \& IVARS, José. Towards a sustained competitiveness of Spanish tourism. In: APOSTOPOULOS, Y.; LOUKISSAS, P. \& LEONTIDOU, L. (orgs.). Mediterranean Tourism: Facets of Socioeconomic Development and Cultural Change, Londres: Routledge. 2001.

MUNT, Ian. The "Other" Postmodern Tourism: Culture, Travel and the New Middle Classes. Theory, Culture E Society, vol. 11, 1994, p. 101-123.

OBRADOR PONS, Pau. Being-on-holiday: tourist dwelling, bodies and place Tourist Studies, vol. 3 n. 1, 2003, p. 47-66.

A haptic geography of the beach: naked bodies, vision and touch. Social and Cultural Geography, vol. 8, n. 1, 2007, p. 123-141.

PEMBLE, John. The Mediterranean Passion. Oxford: Claredon, 1987.

RITZER, George. The McDonalisation of Society. Londres: Sage, 1993

\& LISKA, Allan. "McDonalisation" and "post-tourism": complementary perspectives on contemporary tourism. In: ROJEK, Chris \& URRY, John (orgs.). Touring Cultures. Londres: Routledge, 1997. 
ROJEK, Chris. Ways of Scape. Londres: Routledge. 1993.

SAVAGE, Mike; BAGNALL, Gaynor \& LONGHURST, Brian. Globalization and Belonging. Londres: Sage, 2004.

SHAW, George \& WILLIAMS, Allan. The Rise and Fall of British Seaside Resorts. Londres: Thomson Learning, 1997.
SMITH, Andrea. Colonial Memory and Postcolonial Europe. Maltese Settlers in Algeria and France. Bloomington: Indiana University Press, 2006.

URRY, John. The Tourist Gaze. Londres: Sage, 1990.

WALLERSTEIN, Immanuel. Historical social science. The British Fournal of Sociology, vol. 51, n. 1, 2000.

\section{Resumo}

Os estudos do turismo destacam a busca pela novidade e o exótico, enfatizando o papel da classe social na determinação de sensibilidades estéticas. Este artigo problematiza tal postura por meio do exame empírico dos sentimentos e práticas levados a cabo por turistas no Mediterrâneo espanhol. Sugere-se que, para compreender mudanças culturais e ambientais no turismo daquela região, é preciso focar na relação entre sensibilidades estéticas, sentidos de pertencimento e redes sociais. Conclui postulando que estudos do turismo devem levar a história mais fortemente em conta para compreender pontos de inflexão críticos e dependências de trajetória a influenciar transformações da paisagem.

Palavras-chave: turismo de massa; pertencimento; memória; paisagem; Mediterrâneo.

\section{Abstract}

Tourism studies have highlighted the quest for novelty and the exotic in the tourist experience and have given a prominent role to class-determined aesthetic sensibilities in the consumption of places. This paper engages with these debates through empirical examination of the feelings and practices of tourists in the Spanish Mediterranean. The existing literature ignores the complex ways in which holiday destinations are entangled in generational change, mobility patterns and perceptions of landscape dynamics. It concludes by advocating a type of tourism studies that take history seriously in order to understand critical turning points and path dependencies in landscape change.

Key-words: mass tourism; belonging; memory; landscape; Mediterranean Sea. 


\section{Javier Caletrío}

\section{Résumé}

Les études du tourisme ont mis en évidence la quête de la nouveauté et de l'exotique dans l'experience touristique et ont donné un rôle de premier plan aux sensibilités esthétiques de la consommation des lieux déterminées par la classe. Cet article engage à ces débats par l'examen empirique des sentiments et pratiques des touristes dans la région méditerranéenne espagnole. La littérature existante ignore l'effet des changements de génération, les schémas de mobilité et les perceptions de la dynamique des paysages. Il conclut en préconisant que les études de tourisme doivent prendre au sérieux l'histoire pour comprendre l'évolution du paysage.

Mots-clés: tourisme de masse; appartenant; memoire; paysage; Méditerranée. 